\title{
GUIDELINES TOWARDS AN INTEGRATED OCEAN OBSERVATION SYSTEM FOR ECOSYSTEMS AND BIOGEOCHEMICAL CYCLES
}

\author{
Hervé Claustre $^{(1)}$, David Antoine ${ }^{(1)}$, Lars Boehme $^{(2)}$, Emmanuel Boss $^{(3)}$, Fabrizio D'Ortenzio ${ }^{(1)}$, Odile Fanton \\ D’Andon $^{(4)}$, Christophe Guinet ${ }^{(5)}$, Nicolas Gruber ${ }^{(6)}$, Nils Olav Handegard ${ }^{(7)}$, Maria Hood ${ }^{(8)}$, Ken Johnson ${ }^{(9)}$, Arne \\ Körtzinger $^{(10)}$, Richard Lampitt ${ }^{(11)}$, Pierre-Yves LeTraon ${ }^{(12)}$, Corinne Le Quéré(13), Marlon Lewis ${ }^{(14)}$, Mary-Jane \\ Perry $^{(15)}$, Trevor Platt ${ }^{(16)}$, Dean Roemmich ${ }^{(17)}$, Shubha Sathyendranath ${ }^{(16)}$, Uwe Send ${ }^{(17)}$, Pierre Testor $^{(18)}{ }^{\text {, Jim }}$ \\ Yoder $^{(19)}$ \\ (1) CNRS and University P. \& M. Curie, Laboratoire d'Océanographie de Villefranche, 06230 Villefranche-sur-Mer, \\ France, Email: claustre@obs-vlfr.fr; antoine@obs-vlfr.fr ; Dortenzio@obs-vlfr.fr \\ ${ }^{(2)}$ NERC Sea Mammal Research Unit, Scottish Oceans Institute, University of St Andrews, St Andrews, Fife KY16 8LB, \\ Scotland, UK, Email: Ib284@st-andrews.ac.uk \\ (3) University of Maine, School of Marine Science, Orono, ME 04469 USA, Email: emmanuel.boss@maine.edu \\ (4) ACRI-ST, 260, route du Pin Montard - B.P. 234, 06904 Sophia Antipolis Cedex, France, Email: oha@acri-st.fr \\ ${ }^{(5)}$ CNRS, Centre d'Études Biologiques de Chizé, Villiers-en-Bois, 79360 Beauvoir-sur-Niort, France, \\ Email: christophe.guinet@cebc.cnrs.fr \\ ${ }^{(6)}$ Institute of Biogeochemistry and Pollutant Dynamics, ETH Zurich, Universitatstrasse 16, 8092 Zurich, Switzerland, \\ Email: Nicolas.gruber@env.ethz.ch \\ (7) Institute of Marine Research, Postboks 1870 Nordnes, 5817 Bergen, Norway, Email: nilsolav@imr.no \\ ${ }^{(8)}$ UNESCO-IOC, 1 Rue Miollis, 75732 Paris cedex 15, France, Email: maria.hood@ioccp.org \\ (9) Monterey Bay Aquarium Research Institute, 7700 Sandholdt Road, Moss Landing, CA 95039, USA, \\ Email :johnson@mbari.org \\ ${ }^{(10)}$ Leibniz-Institut für Meereswissenschaften (IFM-GEOMAR) Chemische Ozeanographie, Düsternbrooker Weg 20 , \\ 24105 Kiel, Germany. Email: akoertzinger@ifm-geomar.de \\ ${ }^{(11)}$ National Oceanography Centre, Empress Dock, Southampton, SO14 3ZH UK, \\ Email: r.lampitt@noc.soton.ac.uk \\ ${ }^{(12)}$ Ifremer, Centre de Brest, Plouzané, France, Email : pierre.yves.le.traon@ifremer.fr \\ ${ }^{(13)}$ School of Environment Sciences, University of East Anglia, Norwich, NR4 7TJ, UK, Email: C.Lequere@uea.ac.uk \\ ${ }^{(14)}$ Department of Oceanography, Dalhousie University, Halifax, Nova Scotia B3H 4J1, Canada, \\ Email: Marlon.Lewis@ dal.ca \\ ${ }^{(15)}$ University of Maine, School of Marine Science, Walpole, ME 04573 USA, Email: perrymj@maine.edu \\ ${ }^{(16)}$ Plymouth Marine Laboratory, Prospect Place, The Hoe, Plymouth, PL1 3DH, UK, \\ Email: tplatt@dal.ca; ssat@pml.ac.uk \\ ${ }^{(17)}$ Scripps Institution of Oceanography, University of California San Diego, 9500 Gilman Drive, La Jolla CA 92093 - \\ 0230 USA, Email: droemmich@ucsd.edu; usend@ucsd.edu \\ ${ }^{(18)}$ LOCEAN-IPSL/CNRS, Université Pierre et Marie Curie, Paris, France, Email: testor@locean-ipsl.upmc.fr \\ ${ }^{(19)}$ Woods Hole Oceanographic Institution, MS \#31, Woods Hole, MA 02540 USA, \\ Email: jyoder@whoi.edu
}

\begin{abstract}
The observation of biogeochemical cycles and ecosystems has traditionally been based on ship-based platforms. The obvious consequence is that the measured properties have been dramatically undersampled. Recent technological advances in miniature, low power biogeochemical sensors and autonomous platforms open remarkable perspectives for observing the "biological" ocean, notably at critical spatio-temporal scales which have been out of reach until recently. The availability of this new observation technology thus makes it possible to envision the development of a globally integrated observation system that would serve both scientific as well as operational needs. This in situ system should be fully designed and implemented in tight synergy with two other essential elements of an ocean observation system, first satellite
\end{abstract}

ocean color radiometry and second advanced numerical models of biogeochemical cycles and ecosystems.

This paper gives guidelines and recommendations for the design of such system. The core biological and biogeochemical variables to be implemented in priority are first reviewed. Then, the variables for which the observational demand is high although the technology is not yet mature are also identified. A review of the five platforms now available (gliders, floats, animals with sensors, mooring at eulerian site and ships) identifies their specific strengths with regards to biological and biogeochemical observations. The community plans with respect to ongoing implementation of these platforms are pointed out. The critical issue of data management is addressed, acknowledging that the availability of tremendous amounts of data allowed by these technological advances will require an 
extraordinary effort on behalf of the community with respect to data management, i.e. data availability in open access and the development of various quality control procedures (in real time as well as delayed mode).

Because physical forcing determines the response of the biological and biogeochemical system, it is possible and highly desirable for maximum utility that the new technology will allow the measurement of physical and biological variables to be conducted at the same resolution. Similarly, the obvious complementarities between satellite ocean color radiometry, which is synoptic but limited to the surface layer, with in situ measurements, which extend the satellite data into the ocean interior, have to be the starting point for developing fully 3D/4D assimilative forecasts of the biological ocean. Finally, while implementing a globally integrated system is obviously the long-term target for our community, we recommend starting "simple" by implementing the concept of such an integrated system first at the regional scale. It is proposed to begin to study regional biogeochemical hot spots of global relevance. For example, the Eastern boundary currents with associated oxygen minimum zones, as well as the North Atlantic, could represent interesting "super site" case studies where an international coordinated effort could be undertaken for such "prototype" integrated systems to be set up.

\section{AN UNDER-SAMPLED OCEAN: CONTEXT AND CHALLENGES}

Physical forcing of the upper ocean accounts for much of the variability in oceanic biological and biogeochemical (thereafter denoted by "bio") processes; in particular, it is responsible for nutrient injection in upper sunlit layers, which scales the level of photosynthetic production and hence elemental cycling, ecosystem structure, and the magnitude of living resources. Because climate change affects physical forcing (magnitude and variability) it is likely to alter the oceanic "bio" response. Physical forcing (and associated "bio" responses) occurs over a continuum of spatial (sub-meso-/ meso-/ basin/ global) and temporal (diurnal, seasonal, decadal) scales.

With respect to oceanic observations required to evaluate our changing oceanic environment, the last century can be described as a century of undersampling [1]; this is especially true for biology and biogeochemistry. Our current understanding mostly relies on ship-based observations and a few time series. A large part of the variability in oceanic "bio" processes has not been captured in the loose net of this traditional sampling.

Rapid technological advances in ocean observation have nevertheless been achieved during the last decade, particularly with respect to physical climate variables.
For example at the end of 2007, the international Argo (Global array of free-drifting profiling floats) program reached its goal (defined 8 years before) of deploying over 3000 autonomous profiling floats worldwide which are now regularly collecting temperature and salinity profiles ocean wide [2]. Within a few years, with such an exemplary program, physical oceanographers have been able to acquire tremendous amounts of data, allowing a variety of topics to be addressed, from the evolution of water mass properties as a result of climate change to the initialization and validation of models, including operational ones.

With a certain time lag, biological and biogeochemical oceanography is following a similar technological path. Thanks to the miniaturization of "bio" sensors, oceanographers are beginning to develop and deploy "bio" floats [3, 4 and 5] or gliders [6, 7 and 8], which allow new observational scales in ocean biology and biogeochemistry to be tackled. In parallel, certain marine mammals have now been equipped with "bio" sensors allowing sustained data acquisition to be initiated in areas where data scarcity is generally the rule [9]. Biological and biogeochemical oceanography are thus emerging from their data-limited foundations.

Based on these technologies, pilot projects have been launched or are planed [9, 10, 11, 12 and 13]. If, from these individual initiatives and from pilot projects, we begin to think and implement networks and arrays and coordinate the efforts at the international level to minimize duplication of these efforts and maximize yield, we can expect a revolution in biological and biogeochemical oceanography. The community will have access to an unprecedented observational array of vertically-resolved "bio" variables. Developing such an in situ automated observation system will constitute an essential step towards a better understanding of biogeochemical cycles and ecosystem dynamics, especially at spatial and temporal scales that have been unexplored until now. The present paper is focused on providing guidelines for implementing such a system over the next decade.

Two main outcomes can be expected from a welldesigned integrated observation system. The scientific outcomes include a better exploration and an improved understanding of both present state and change and variability in ocean biology and biogeochemistry (over a large range of spatial and temporal scales) [14]. Associated with this, the reduction of uncertainties in the estimation of biogeochemical fluxes is an obvious target. Besides these primary scientific objectives, the operational (long-term) outcomes are the development of skillful predictions of ocean biogeochemistry and ecosystem dynamics as well as the delivery of real-time and open-access data to scientists, users and decision makers. Reduced uncertainties result in better policy. 
Both scientific and operational objectives require the in situ system to be designed and implemented in tight synergy with two other essential bricks of an integrated ocean observation system: modeling and satellite observation.

Modeling biogeochemical cycles is now moving from an era of "simple" NPZD (Nitrate-PhytoplanktonZooplankton-Detritus) models [15] towards more complex models, the so-called Dynamic Green Ocean Models (DGOMs) taking explicitly into consideration the physiology of marine organisms through their grouping into plankton functional types (PFTs) [16]. The elaboration of this new class of models has benefited from improved availability of "bio" data required to parameterize and validate/evaluate them. The increase in complexity in biogeochemical models can help progress towards the resolution of important scientific questions in two distinct domains: climate change and the availability of food resources. In the climate change domain the models can help quantify the feedbacks between high $\mathrm{CO}_{2}$ (carbon dioxide) and marine ecosystems, including those mediated by surface warming, changes in ocean circulation and ocean acidification. Current global biogeochemical models are particularly suited to assess the potential for ecosystems to amplify or dampen global warming through their impact on climate-relevant gases such as $\mathrm{CO}_{2}$, dimethylsulfide (DMS) and nitrous oxide $\left(\mathrm{N}_{2} \mathrm{O}\right)$. The models can also help to determine the factors that control global and regional marine biomass, the stability of marine ecosystems and their resilience to environmental change, and the availability of food for fish/seafood larvae, higher predators and humans.

Models can only provide useful answers if there are sufficient data to constrain the underlying processes and validate the model output. New approaches to assimilate biological and chemical data into these models are advancing rapidly [17]. Notably, the progressive integration of biogeochemical variables in the next generation of operational oceanography systems is one of the long-term objectives of the GODAE (Global Ocean Data Assimilation Experiment) OceanView international program. Nevertheless, and in view of refining these models for improving their representativeness and predictive capabilities, the presently available datasets remain too scarce. There is an obvious and imperative need to reinforce biological and biogeochemical data acquisition and to organize databases [18].

The pessimistic view of an under-sampled ocean with respect to its biogeochemical properties has to be tempered however since the availability of satellite ocean color radiometry (OCR) data. Satellite OCR is the only observational tool that can make synoptic measurements of the global ocean related directly to ecological and biogeochemical processes. Satellite OCR is now central in oceanographic research, particularly in studies of variability at meso-scale $(10-100 \mathrm{~km})$ to ocean basin spatial scales and time scales ranging from days to inter-annual [19]. Global estimates of ocean primary production are now based on satellite OCR (Ocean Colour Radiometry) data [20, 21, 22 and 23]. Time series have been built, from which climate-relevant trends can be extracted [24, 25, 26 and 27]. In situ and satellite data are highly complementary. Whereas in situ data extend the satellite information into the ocean interior (unseen by the remote sensor) and provide indispensable sea truth data, the satellite data fills the gap of poor spatio-temporal resolution of in situ data. Besides Chl $a$, new «satellite» biogeochemical and ecosystem-related products are now becoming available [10 and 28], that also usefully serve the data requirements of the modeling community.

Taking into consideration that automatic in situ acquisition and remotely-operated platforms appear as the future solution to (at least partly) circumvent the issue of under-sampling biogeochemical and ecosystem variables, the present paper aims at making the appropriate recommendations for developing and maintaining a sustained in situ observation system. It is organized as follows. We first identify the key variables, whose scientific relevance is acknowledged and whose autonomous measurements are now mature enough to become core variables of a future integrated observation system. We then complement this analysis by the review of other essential variables for which technologic refinement or even development are still required over the next decade to realize the goal of full integration. The different observation platforms of the future ocean observation system are then presented with five in situ elements (floats, gliders, animals, timeseries, ship repeated transects) complemented by OCR satellite. We emphasize the critical issue of developing and implementing a dedicated data management system, which will be crucial for the operational and scientific success of this future observation system. Various aspects of the integration of the different components of the observation system are then analyzed in the context of developing synergies for the benefit of observation and scientific outputs. The paper concludes with a summary of recommendations.

\section{SELECTING THE CORE "BIO-VARIABLES"}

\subsection{The core ecosystem and biogeochemical variables: which ones now?}

Besides their scientific relevance (in particular with respect to modeling requirements) the key biogeochemical and ecosystem variables discussed here are primarily selected because they are amenable to non-intrusive and automatic measurements, ideally through miniature, low-power, in situ sensors (already developed or in development). Variables requiring 
water collection and sample manipulation, although essential in any sustained observation systems, are not considered in what follows (but will be evoked later, in particular for the issues of sensor calibration and for ship-based investigations).

\subsubsection{Chemical variables and variables of the $\mathrm{CO}_{2}$ system}

Nitrate. Nitrate is a key variable in ocean biogeochemistry and is an essential state variable of biogeochemical models [18]. Low concentrations in about $60 \%$ of the ocean limit rates of new primary production. In the remaining $40 \%$, changes in nitrate can be used as a tracer of new primary production [29]. Optical sensors for dissolved nitrate are now available [30]. In combination with autonomous platforms, this sensor can be used to track nutrient injection events that may stimulate productivity in oligotrophic regions [31] or to map plankton metabolism [32].

Oxygen. The oceanic dissolved oxygen concentration is a key quantity for ocean ecology and biogeochemistry. It permits study and quantification of a diverse and crucial set of processes, such as the magnitude and variability of net community and export production, the detection of the impact of global warming on ocean biogeochemistry and circulation, the assessment of changes in low oxygen regions, and improved estimates of the oceanic uptake of anthropogenic $\mathrm{CO}_{2}$ [14]. Dissolved oxygen sensors that are both precise and stable over extended periods have been recently developed. They can be easily integrated with the currently-used Argo (Array for Real-time Geostrophic Oceanography) floats. A few issues remain with respect to the overall accuracy and time constant of the sensors. In this regard further improvement is needed. Also, various calibration methods (laboratory vs. in-situ, potential use of atmospheric oxygen measurement by optode sensor as drift control, etc.) need to be further developed. In general, the sensor status currently achieved for autonomous measurement of oxygen in the ocean is impressive and perhaps most advanced in the realm of chemical sensors.

$\mathrm{CO}_{2}$ system at fixed depth. Systematic and accurate measurements of variables of the $\mathrm{CO}_{2}$ system are essential to document the evolving response of the ocean to anthropogenic inputs of carbon dioxide. Autonomous sensors for long-term subsurface measurement of the $\mathrm{CO}_{2}$ partial pressure $\left(p \mathrm{CO}_{2}\right)$ have been commercially available for some time now. Two rather different measurement principles are followed: (1) Equilibration of a $\mathrm{pH}$ indicator dye solution (with specifically adjusted alkalinity) through a silicone membrane tube with ambient seawater. Depending on ambient $p \mathrm{CO}_{2}$, a $\mathrm{pH}$ change in dye solution occurs that can be detected spectrophotometrically through variations in the concentrations of the corresponding dye species. (2) Membrane-based air-seawater equilibration with subsequent measurement of $\mathrm{CO}_{2}$ concentration in the equilibrated gas by non-dispersive infrared detection (NDIR).

Both approaches can be used for subsurface $p \mathrm{CO}_{2}$ measurements over extended period between several months to about 1 year. These sensors have been shown to be of great use in observing ocean variability such as on seasonal timescales [33 and 34] from stationary platforms such as moorings. The achievable accuracy is nevertheless significantly inferior to what is currently achieved with shipboard underway $p \mathrm{CO}_{2}$ instruments based on air-water equilibration ( 2-3 $\mu$ atm).

\subsubsection{Bulk bio-optical variables}

Chlorophyll a is the discriminative proxy for phytoplankton biomass, a key variable in biogeochemical studies. It can be measured by fluorescence. Miniature fluorescence sensors are available to be mounted on a variety of platforms (e.g. gliders, floats, animals) [4 and 8]. When converting to biomass several issues need to be taken into account, e.g. variable pigment/carbon ratio and variable fluorescence/chlorophyll concentration ratio due to nonphotochemical quenching, species composition, and temperature. Noticeably, the interpretation of fluorescence data would be significantly enhanced if they can be calibrated using chlorophyll concentration measurements from discrete samples.

Optically-resolved Particulate Organic Carbon (POC). In open ocean waters, POC is the main source of particles and the load in particles is the main driver of water turbidity or transparency. Turbidity can be quantified by the measurement of the backscattering coefficient (backscattering-meter), while transparency is measured by the particle attenuation coefficient (transmissometer). Both optical measurements can be converted to a concentration of POC with a reasonable accuracy [5]. Variability in the conversion factor exists due to potential presence of inorganic compounds (e.g. cocolithophores' lith) and variability in size and composition in the POC.

\subsection{The core ecosystem and biogeochemical variables: which ones next?}

Because a very long time frame is involved from the bench-top prototypes to operational sensors [35], few variables are amenable to automatic in situ measurements by remotely-operated platforms. There is nevertheless very active research aiming at rendering other key variables amenable to autonomous sensorbased detection. The degree of sensor maturity depends on the targeted variable. Following is a short review on present status and on-going and planned development with respect to other key measurements. 


\subsubsection{Variables of the $\mathrm{CO} 2$ system over the vertical dimension}

It is essential to reinforce sensor development, allowing the density of global and accurate ocean carbon measurements to be increased, including in the ocean interior [36 and 37]. Ion-sensitive field-effect transistor (ISFET) $\mathrm{pH}$ sensors appear to have sufficient stability $(<0.01 \mathrm{pH})$ for multi-year operation on profiling floats. However, the chip packaging that enables long-term stability [38] is not tolerant to high pressure. Improved packaging systems must be developed.

With respect to the use of $\mathrm{pCO}_{2}$ sensors by autonomous profiling platforms such as floats and gliders, major obstacles exist and need to be overcome. These include the long time constants of the sensors (typically $>10$ min) as well as their comparatively large size and power consumption [36]. Furthermore, their temperature and pressure hysteresis need to be better characterized. Several of these aspects are currently being worked on and major improvements can be expected in the near future. First field deployments of autonomous membrane-based $p \mathrm{CO}_{2}$ sensors on profiling floats are currently being carried out at the Cape Verdean longterm Ocean Observatory (Fiedler \& Körtzinger, unpublished). The results are promising in general but also point to major improvements of the technology that need to be made. It remains to be seen whether the time constant aspect can be solved to the level desired for profiling float applications (i.e. < approx. $5 \mathrm{~s}$ ).

\subsubsection{Nutrients}

New insights into global geochemical cycles definitively require the use of in situ nutrient sensors. The wet techniques exhibit the best accuracy and have demonstrated their reliability, although possible drift of standards over long-term deployment might be an important issue [39]. Alternative techniques might involve optical (e.g. for nitrate) or potentiometric (e.g. for ammonia) measurements. Resources must be expended to address critical sensor development needs that include reductions in size, cost, power consumption, reagent use and waste generation, and increase in long-term reliability. During the next decade, the transition of nutrient sensors from research to commercial devices is likely to continue. It will be, in particular, based on the fast growing microsystem technology (MST). MST application to in situ oceanographic sensing is in its infancy, but survival and operation at depth has been demonstrated [39].

\subsubsection{Plankton or particulate functional types}

Biogeochemical models have specific requirements with respect to the key plankton or particle functional types that should be measured [10]. Monitoring plankton or particle functional types is challenging and requires high resolution imaging systems together with dedicated data analysis systems. Presently, the degree of maturation of these developments is variable according to the particle or plankton size class that is sensed by this emerging instrumentation [40].

For plankton or particles greater than $20 \mu \mathrm{m}$ various systems have been developed. The rapid advances in electro-optical technology have resulted in new and better ways of illuminating, detecting and imaging plankton in situ. Prototypes or commercially available high resolution imaging systems now allow plankton and particles to be detected across a wide range of size (up to the $\mathrm{cm}$ scale for some instruments). While the hardware part of these systems is now maturing, some additional miniaturization efforts are still required for these sensors to become fully adaptable on autonomous platforms (e.g. floats and gliders,). A good example for such miniaturization is the Laser optical plankton counter which enumerates and sizes particles and plankton in the $100 \mu \mathrm{m}-1 \mathrm{~cm}$ range and has been successfully deployed for several days on profiling floats [41]. Similarly, although recognition of phytoplankton [42] and zooplankton [43 and 44] begin to be possible, data analysis and software systems still need some additional maturation [40].

Plankton organisms smaller than about $20 \mu \mathrm{m}$ (picoand nano-size range), which includes prokaryots and protists, have generally simple shapes (round, oblong) not useful for taxonomic discrimination. In such cases, the use of flow cytometry appears to be the only way to automatically access taxonomic information in this size range. In situ flow cytometers represent a promising avenue in this respect, although their size and energy consumption prevent them, for the moment, to be part of operational open ocean observation systems. With respect to coccolithophorids, the use of birefringence properties of their carbonate shells might be a way to discriminate them from the background of nano-sized phytoplankton cells [40 and 45].

\subsubsection{Mid-trophic Automatic Acoustic Sampler for meso-zooplancton and micronecton}

Hydroacoustic sensors offer unique possibilities for remote sensing of marine life on various scales, extending from basin scale observations at low frequencies (100s of $\mathrm{Hz}$ ) [46] to small scale-highfrequency $(\mathrm{mHz})$ acoustics for detailed observations (mm scale), often coupled by optical sensors [47].

The ecosystem approach to fisheries management has shifted the focus from traditional single species management to an overall evaluation of the ecosystem [48], including the effects of climate change. As a response, modeling approaches that couple traditional population-, biogeochemical-, and ocean-circulationmodels are emerging [49]. These models have identified the mid-trophic level as a critical gap that needs to be addressed. 
Hydroacoustic has matured to a standard tool for quantifying marine life [50], and is well suited to observe the mid-trophic levels [51]. Presently used systems [52] are large and expensive and thus need connection to shore and/or routine tending or have short operational times. Low cost low power transducers are currently available, and mounting them to floats is a realistic option now.

\section{THE VARIOUS PLATFORMS IN SUPPORT OF AN OBSERVATION SYSTEM.}

In complement to ocean color satellite observation of the ocean surface, there are five main sampling platforms on which a future observation system dedicated to ocean biogeochemistry and ecosystem could be anchored. These emerging or already existing platforms are detailed hereafter. For each, a brief summary is given with respect to its main spatiotemporal range of application and specific potential as well as constraints. When possible, suggestions regarding a future implementation plan, corresponding to the whishes of the community, are also tentatively given.

\subsection{A "bio" profiling float array.}

Thanks to the miniaturization of sensors, biological and biogeochemical oceanographers are beginning to follow the way of physical oceanography with Argo floats and to undertake a similar technological leap by developing and deploying "bio" floats. The proof-of-concept of these floats has been demonstrated for several types of applications. Floats with oxygen sensors have been used to document ventilation processes in the Labrador Sea [3] whereas time series observations performed by similar floats in the Pacific subtropical gyres have allowed the quantification of Net Community Production over several seasonal cycles [53]. Optical sensors have been implemented on profiling floats allowing key processes to be addressed (e.g. production, export) related to the carbon biogeochemical cycle [5]. A 3-year time series of Chlorophyll a and backscattering (a proxy for POC) was acquired in the North Atlantic using a profiling float equipped with optical sensors [4]. Nitrate sensors are currently deployed on floats and operated successfully for $>500$ days [12]. It therefore appears that the technology is now mature and has a great potential for the development of an array of "bio" floats. The rationale for the development / deployment of such floats is to provide the biogeochemical community with an unprecedented number of vertical profiles of (real-time) key biogeochemical quantities. At present, the variables that are beginning to be routinely acquired by profiling floats (and identified as core variables, see above) are $\mathrm{O}_{2}$ [11], bio-optical variables (Chlorophyll $a$ as well as optically-resolved POC; [10]) and $\mathrm{NO}_{3}$ [12] (Fig 1). All these variables are essential for the understanding and modeling of biogeochemical cycles and ecosystems dynamics [10].

In conjunction with this technological development, the community of potential users is beginning to coordinate itself. A community user group "the friends of oxygen on Argo" has written a white paper, which gives the foundations for an oxygen float array development [11]. The International Ocean Color Coordinating Group (IOCCG) is funding the Bio-Argo working group, which provides recommendation for the development of a bio-optical float array as a synergistic complement in the ocean interior to remotely-sensed bio-optical variables [10]. Similarly some recommendations were formulated as a follow-up of an US Ocean Carbon and Biogeochemistry meeting on profiling floats (and gliders) [12]. The community is presently relying on these various coordination efforts to envisage the implementation of a "bio" float array. The profiling float technology being the most cost-effective one to acquire biogeochemical data at global scale, the final and natural objective is to implement progressively a global "bio" float array. Nevertheless, prior reaching this ambitious target, the feasibility of such system has to be demonstrated at a reasonable scale. Thus, the community of potential users plans to implement one or two pilot projects on targeted areas of biogeochemical relevance and where some key issues of the system

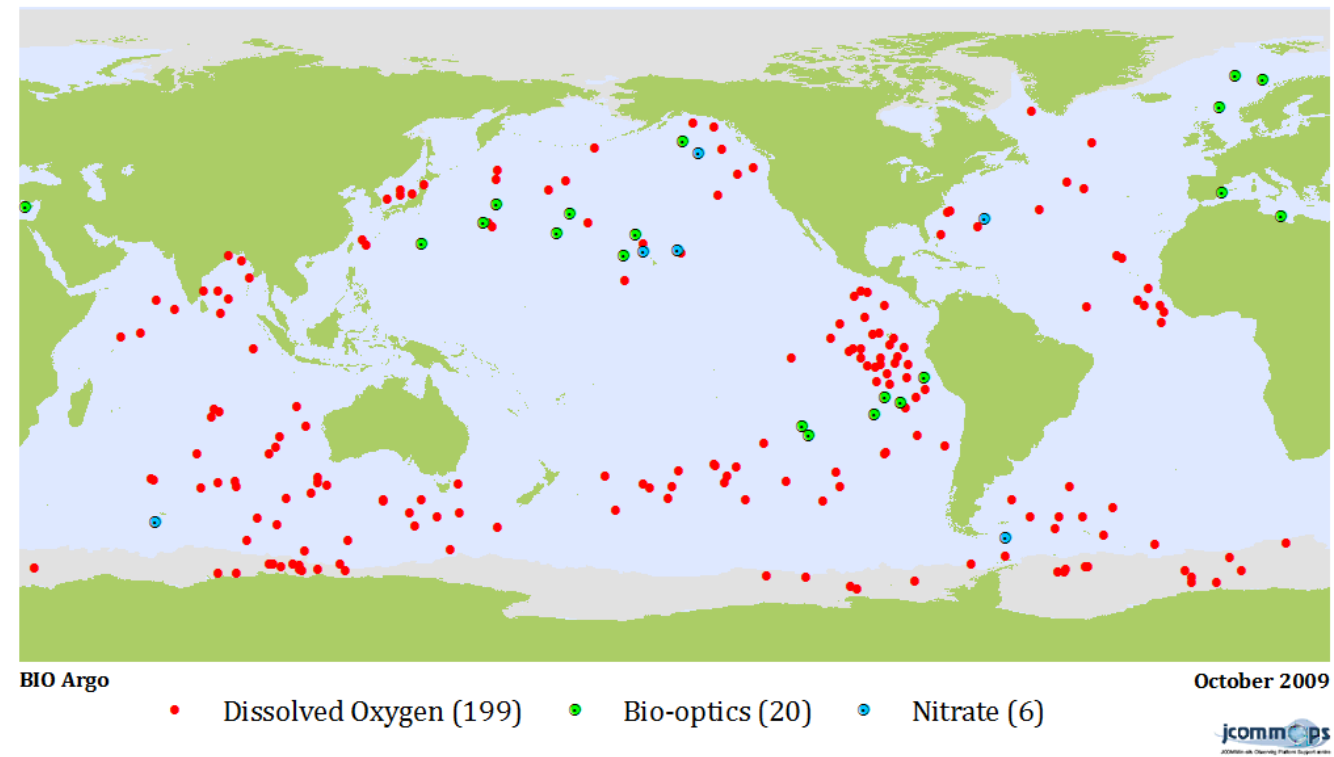

Figure 1: Status of profiling floats with biogeochemical and / or bio-optical sensors in October 2009. 
operation could be tested, namely (1) that the sensor accuracy and stability are sufficient for stated scientific objectives and (2) that the community can implement real-time and delayed mode quality-control capabilities.

\subsection{A "bio" glider network}

Gliders can be steered and maintained in particular areas providing the spatial structure for all variables measured by the sensors on-board, at relatively slow speed $(30 \mathrm{~km}$ day $^{-1}$ horizontally). Only ten years ago, underwater gliders were making history with their maiden deployments, lasting only hours to several days, and initially measuring only temperature and salinity. Since then many more sensors have been specifically designed to meet the stringent specifications for low power provide bulk information on zooplankton biomass [6]. "Bio" gliders in ocean observing would complement "Bio" floats, providing more flexibility in applications where the ability to navigate is essential. Several key areas or processes could be targeted by "bio" glider deployment as part of a sustained network.

"Bio" gliders are suitable platforms for any sustained observational system aimed at monitoring bio-physical coupling at the coastal interface between shelf and open ocean. It is essential to monitor this interface for improved understanding of biogeochemical cycles and biological resource dynamics. It is also a place where harmful algal blooms may develop. There is a strong societal demand to address these issues (forecast, mitigation), which requires enhanced biophysical

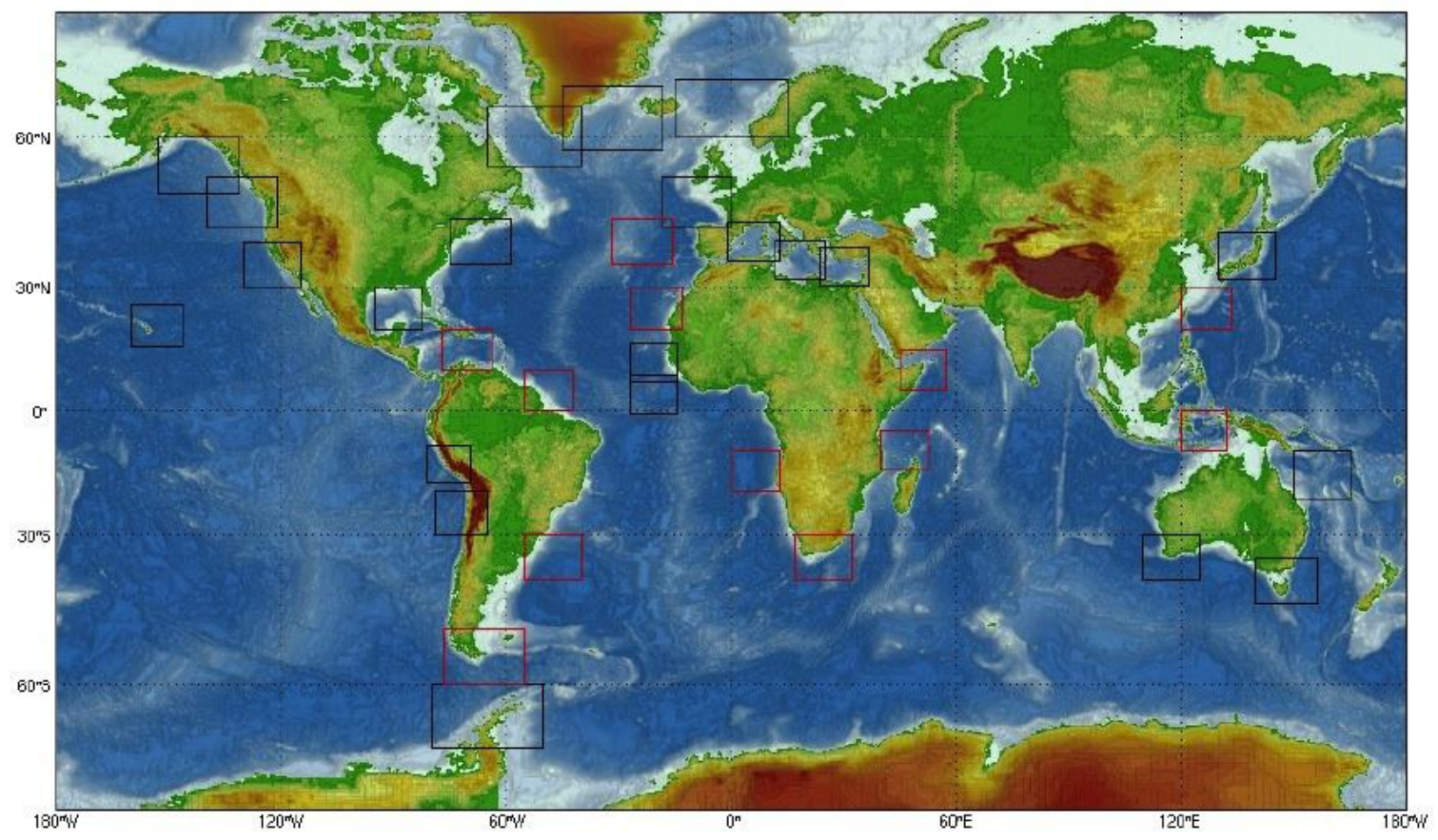

Figure 2: Map showing the geographical coverage of a future glider network (possibly including a biogeochemical payload). Black boxes correspond to regions where gliders have been already deployed. Red boxes identify additional sites of interest for future deployments. The size of the boxes is $1000 \mathrm{~km} x 1000 \mathrm{~km}$. After [13].

consumption and small size for use in gliders. The accounts of successful missions, lasting months in duration with operations in remote and hostile environments, continue to grow. Gliders are now technologically mature and ready to be incorporated into sustained ocean observing programs, and have continued use in experimental process studies [13].

The same basic and core variables are now potentially measurable from gliders as for "bio" floats, i.e. O2, Chla, optically-resolved POC [6, 7 and 8] and soon, very likely, $\mathrm{NO}_{3}$ (Johnson, unpublished). Acoustic backscattering measurements have also been used to monitoring capabilities in these a priori sensitive areas.

"Bio" gliders appear particularly essential for investigating eastern boundary currents. These systems are the place of the most productive large marine ecosystems in the world (20\% of the global fisheries) due to upwelling phenomena. They are also the place of oxygen minimum zones (OMZs), which, despite representing less than $0.1 \%$ of the global ocean volume are of recognized global biogeochemical and climatic importance. The expansion of these OMZs and associated feedback (on biogeochemistry and biodiversity) is of great concern. Enhanced observations 
are essential and "bio" gliders appear as key platforms for attaining observational capabilities for these critical areas which are very difficult to monitor in a sustained way, since floats drift away with currents from these divergence systems.

Finally, "bio" gliders are ideal platforms for biophysical investigations at sub-meso / meso scale $(1 \mathrm{~km}-$ $100 \mathrm{~km}$ ) which are critical for studies of biogeochemical cycles and ecosystems. Indeed, physical processes at these scales might significantly influence nutrient injection into the upper layers, and hence phytoplankton new production and the subsequent export of newlyformed material to the deeper layers. Our present understanding of the bio-physical coupling at these scales, however, mostly derives from numerical experimentations [54] highlighting the stimulation of production by submesocsale physical processes. There are few validation observations of these finding and "bio" glider studies would be perfectly adapted to this important research area.

Contrary to a float, which may be lost (but sometimes recovered thanks to two-way communication) a glider can, in principle, always be recovered. This is obviously useful, not only for the calibration of glider sensors but also for cross-calibration, since one could think of gliders steered to meet other biogeochemical platforms (floats, animals, ...) and allowing inter-comparisons.

The improvements in glider technology were accompanied by the emergence of glider ports or centers. These logistical centers, very often in the proximity of a laboratory, are and will be the key locations from which endurance lines between coastal waters and the open ocean as well as the monitoring of eastern boundary currents can and will be implemented. The development of a "global" "bio" glider network in the near-future will have to rely on a cluster of these local, national or international (e.g. Everyone's Gliding Observatories) centers (Fig 2). The endurance ( 4 months) and range $(2000 \mathrm{~km})$ of gliders constrain the locations of sustained deployments (requiring repetitive deployments) but they are already sufficient to allow coverage of large parts of the global ocean. On a longer term and with the continuing improvement of technology (e.g. increasing endurance and range), transoceanic bio-physical repeated transects will likely become possible from glider port to glider port.

\section{3. "Bio" animals in polar latitudes.}

Animal-borne systems nicely complement gliders and floats at polar latitudes. Recently animal-borne instruments have been designed and implemented to provide in situ hydrographic data from parts of the oceans where little or no other data are currently available, e.g. from beneath the ice in polar regions [55 and 56]. Their spatial range depends on the chosen animal species, but they can deliver broad- and smallscale observations.

Specific "bio" sensors are being developed for such applications. Some studies use instruments equipped with single wavelength light sensors to derive chlorophyll a concentrations using a bio-optical model [57]. Other new sensors are being developed specifically for animal applications and the first pilot
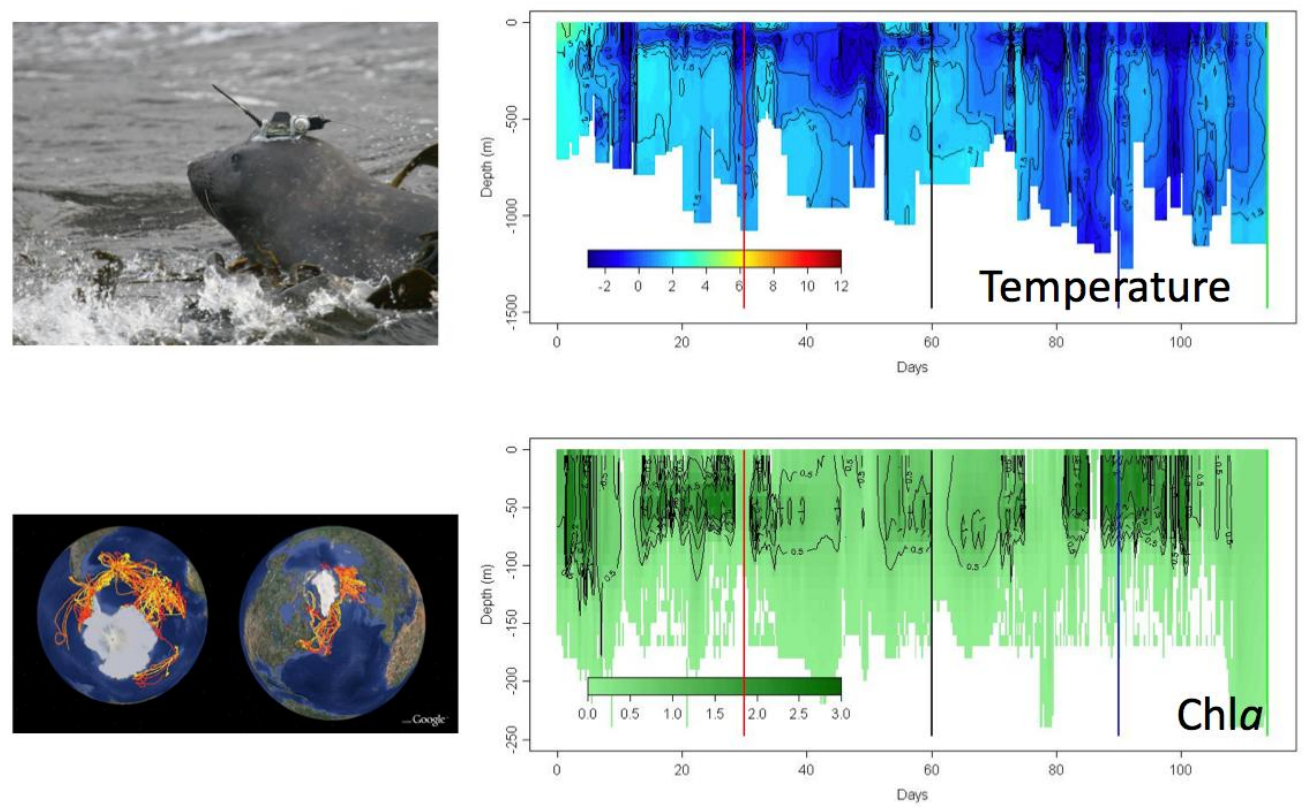

Figure 3: Sea mammals instrumented with Chla fluorescence, temperature and salinity sensors begin to operate in polar areas. As an example, the right panel displays a 120 day temperature (from 0 to $1500 \mathrm{~m}$ ) and Chla (from 0 to $250 \mathrm{~m}$ ) transect between kerguelen plateau and Antarctic Peninsula (back and forth). The bottom left panel (courtesy of Clint Blight-SMRU) display the track of seals instrumented with argos CTD (Conductivity-

Temperature-Depth) tags as part of the SEaOS (Southern Elephant Seals as Oceanographic Samplers) and the MEOP (Marine Mammal Exploration of the Oceans - Pole to Pole) projects (2004-2009). 
study started in 2008 using a CTD (ConductivityTemperature-Depth) sensor and a chlorophyll $a$ fluorometer integrated into a small package, which was deployed on Southern elephant seals at Kerguelen islands [55] (Fig 3). These data are not only used by oceanographers, but also represent a unique combined biological and physical dataset, which is used by marine biologists who study these animal behaviors. As a direct consequence of this developing field, the number of profiles collected by elephant seals for the southern ocean now represents more than $95 \%$ of the CTD and chlorophyll $a$ profiles collected south of $60^{\circ} \mathrm{S}$. Animalplatform technology is thus emerging from its infancy. It is now providing valuable standard oceanographic measurements in remote regions and is also starting to generate biogeochemical datasets.

There are a number of constraints that must be overcome to realize the full potential of animal-borne oceanographic sampling devices. Some are specific to oceanographic sampling from animals, essentially keeping instrument size to a minimum. As an example, miniature $\mathrm{O}_{2}$ optodes are being developed to be specifically implemented on animals. Other issues are linked to the efficiency of data transfer, which will be very likely improved in a near future with the update of the Argo's system (allowing for two-way communications). Finally, ensuring data quality is an especially critical issue as animal-borne instruments are calibrated before deployment, but retrieval of instruments is not always possible (as in the case of floats) for recalibration.

The animal-platform community is in its infancy and no continuous deployments are in place. However, efforts are made to integrate this technology into GOOS (Global Ocean Observing System) as a permanent contributor of ocean data. Animal-borne instruments last typically for one year and provide generally 300$400 \mathrm{~T} / \mathrm{S} /$ fluorescence profiles by deployment until the animals molt again. A minimum number of CTD instruments for GOOS would be about 100 instruments per year to observe both Polar Regions, based on experiences made as part of SEaOS (Southern Elephant Seals as Oceanographic samplers), SAVEX (South Atlantic Variability Experiment) or MEOP (Marine Mammals Exploring the Oceans Pole to Pole) programs. A reasonable target would be to equip $40 \%$ of them with fluorometers. When $\mathrm{O}_{2}$ optode sensors will become suitable for such deployments, their use in this context will also have to be planed.

\subsection{Ship-based hydrographic investigations and "bio" measurements.}

Repeated hydrographic sections were established by the WOCE (World Ocean Circulation Experiment) program and were mainly driven by physical oceanography and the global carbon survey of JGOFS (Joint Global Ocean
Flux Study). Formal organization of the hydrography community has nevertheless been lacking since the end of WOCE (1998), although hydrographic investigations were maintained as part of CLIVAR (Climate Variability and Predictability). This lack of clear international agreement and associated planning has resulted in an inefficient implementation of hydrographic sections with respect to section optimization and data-sharing policies. Following this analysis, the repeat hydrography community is planning a long-term coordination effort to ensure a sustained hydrographic observational activity as a follow-on to CLIVAR [58]. This activity would be organized according to two types of surveys (Fig 4): (1) Decadal surveys, requiring full basin synopticity would be conducted over less than 3 years. (2) Sub-sets of these decadal survey lines would be re-investigated every 2-3 years.

For the biological and biogeochemical communities, an important outcome of this reorganization is that, following recommendations of IOCCP (International Ocean Carbon Coordination Program) and IOCCG, more "bio" variables are to be added to this "redesigned" and more cost-effective observation system.

A first goal of these coordinated ship-based hydrographic investigations is the understanding of the controls and distribution of natural and anthropogenic carbon and biogeochemistry in the ocean interior. Intensification of biogeochemical data acquisition is indeed mandatory in this respect, in particular for a better evaluation of global biogeochemical models, which critically lack data. Whereas the variables of the $\mathrm{CO}_{2}$ system as well as those required to monitor ocean acidification [59] are already considered as core variables of hydrographic sections, the new recommendations emphasize the need for additional biogeochemically-relevant measurements. This includes, notably, some core variables (defined in Sect. 2) such as $\mathrm{O}_{2}$, nutrients, pigments and bio-optical measurements (e.g. Chla fluorescence, transmissiometry). Some of these measurements are relevant to Cal-Val activities of OCR (ground-truthing), whereas others are proxies of phytoplankton functional types (PFT) required for the evaluation of new OCR products and corresponding models.

It is worth recalling that most (if not all) of these "new" measurements are also systematically undertaken as part of SOLAS (Surface Ocean - Lower Atmosphere Study) or IMBER (Integrated Marine Biogeochemistry and Ecosystem Research Project)-relevant cruises. Additionally, the GEOTRACES (Marine Biogeochemical Cycles of Trace Elements and their Isotopes) program has identified some of these "bio" variables (e.g. HPLC (High Pressure Liquid Chromatography) pigments) as core variables to be 


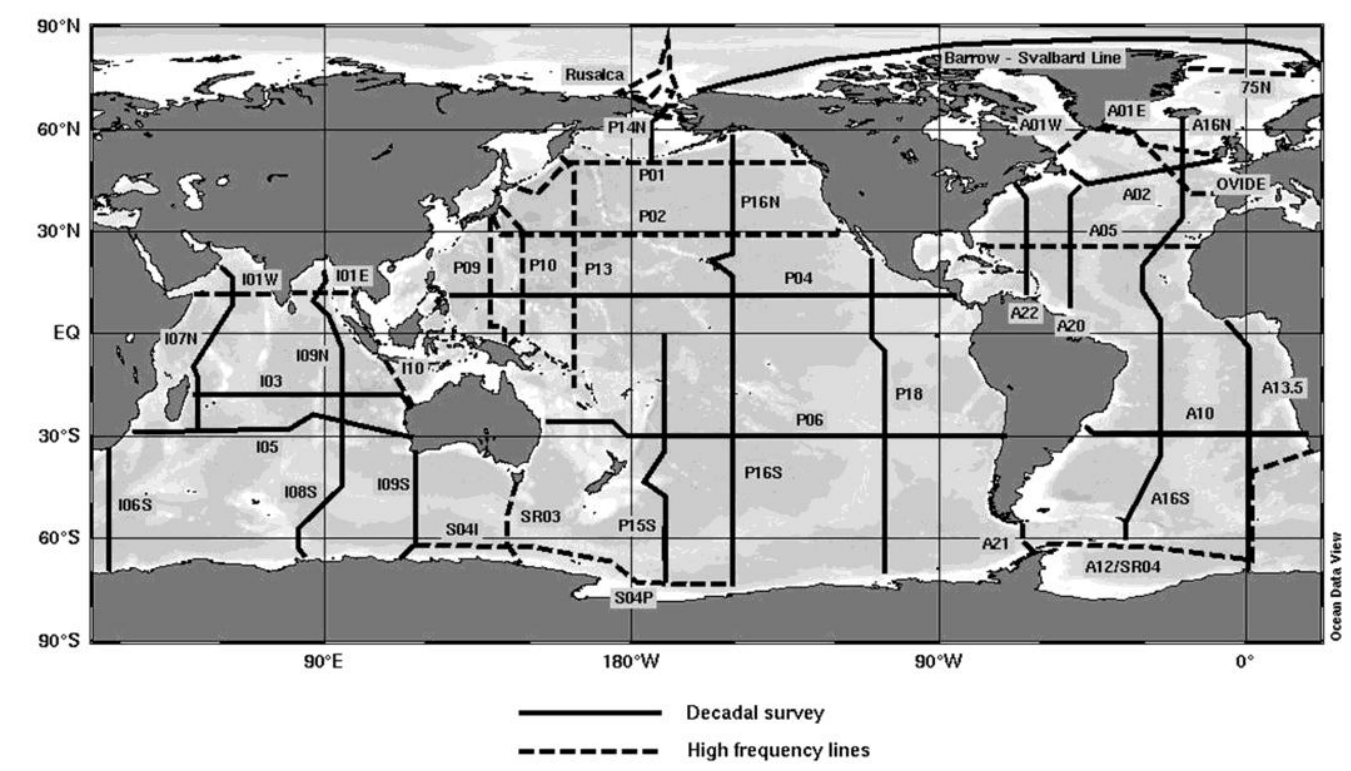

Figure 4: Repeated hydrography cruise plans for the next decade. These cruises will measure some core biogeochemical and bio-optical variables.

measured in complement to the trace elements and isotopes measurements. It is thus obvious that, in the future, ship-based hydrography as well as more processstudy oriented cruises will share a set of common measurements. Planning and coordination to guarantee the best practice in data acquisition and availability is highly desirable. Strengthening and adding value to the coordination effort for hydrographic data acquisition, the GO-SHIP (Global Ocean Ship-based Hydrographic Investigations Program) community is considering data management of Argo and OceanSITES (OCEAN Sustained Interdisciplinary Time series Environment Observation System) program as an example to follow in the future.

Some of the core biogeochemical and bio-optical measurements acquired on these cruises are those also acquired by sensors on autonomous platforms, especially floats. These cruises thus appear as ideal for supporting "bio" float deployments because of the systematic availability of measurements required for sensor evaluation at the time of launch. A close coordination should thus be envisaged with hydrographic section cruises (as well as other cruises) for an optimal planning of float deployments which will, very likely, increase in the near-future.

\subsection{Fixed point (Eulerian) Time series and "bio" measurements.}

The international OceanSITES program integrates a global array of sustained multidisciplinary eulerian observatories [60]. Although this diverse array does not yet have an agreed set of core measurements, this is currently in progress particularly with regard to the "bio" variables. The two main drivers for these observations are to monitor changes in the environment on the annual to decadal scale and secondly to provide insights into system function. This second driver demands a multidisciplinary approach and particularly addresses episodic events which may have a disproportional effect on system function. The OceanSITES infrastructure is common to both of these objectives with high frequency observations (e.g. several times per day), the intention of real time data delivery, an open data policy and data management protocols which are agreed.

The intention is that the present array continues as it is with some additions of sites in specific locations, which have critical attributes and where data are particularly sparse. In addition, a minimal list of state variables is being developed which cover the key properties of each site and which provide a basis for both ocean monitoring and intercomparison between sites. This will probably involve meteorological measurements (heat, wind etc), physical water column properties (current speed at $15 \mathrm{~m}$ depth, profiles of temperature and salinity) and a small number of core biogeochemical variables such as $\mathrm{pCO}_{2}$, oxygen, nutrients and optical measurements of phytoplankton biomass (see Sect. 2). The biogeochemical and ecological properties, which can be reliably measured autonomously, are increasing at a high rate. It is therefore expected that other significant variables will join this minimal list in the next few years. Some of the Ocean Time series have the capability to deploy large and power-hungry instruments allowing detailed investigations of some biological or ecological properties (in situ flow 
cytometer). Nevertheless and in spite of the enhancements which are anticipated with respect to access to "new" autonomous variables, calibration, biofouling [36] and sensor drift still remain significant issues that deserve appropriate investigations for such long term measurements.

For many biogeochemical and ecological properties, the state variables mentioned above is only the first part of the process and the ultimate objective is often to derive rate variables. For example phytoplankton productivity is frequently estimated by a measurement of water fluorescence leading to an estimate of biomass and from that productivity is calculated. The measurement of variables at high frequency is also a way to derivate rates of changes. All steps in the process have large uncertainties and a major challenge which is currently a focus of research and development is to reduce these uncertainties.

At present, 10 to 15 sites in representative biogeochemical provinces are being selected for the progressive implementation of biogeochemical measurements. (Fig. 5).

With respect to protocols for measurements, data quality

\subsection{The Ocean Color Radiometry satellite component}

In the past two decades and particularly since the beginning of the SeaWiFS (Sea-viewing Wide Field of View Sensor) era in 1998, remote sensing of ocean color has become a unique tool by which biologists and biogeochemists have access to global and quasisynoptic measurements of the surface Chla concentration. The use of ocean color remote sensing made it possible to investigate processes ranging from meso-scale [61] to inter-annual and decennial variability [24]. By implementing bio-optical models fed with satellite Chla fields, rates of primary production [21 and 22] as well as phytoplankton loss rates [62] can be determined. Other fundamental biogeochemical quantities have recently begun to be derived from space, such as the particulate organic carbon concentration (POC) [63], the colored detrital [64 and 65], indices of particle size [66] or the phytoplankton community composition [28, 67 and 68]. This is opening new perspectives for the understanding of biogeochemical cycling at regional and global scales.

Before the end of the present decade, the OCR community could have access to data acquired from

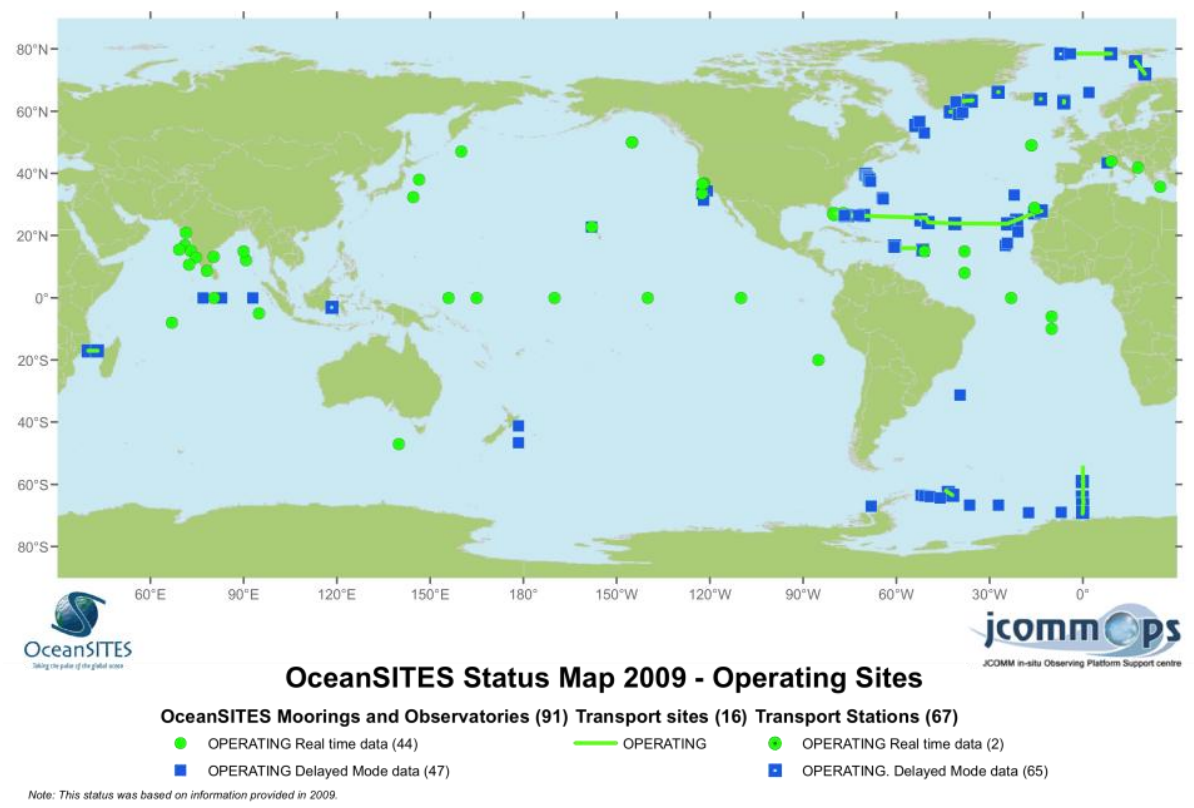

Figure 5: Current status of OceanSITES based on a census of sites/operators that are willing to participate in the project and make their data publicly available to the OceanSITES data system.

control and distribution, OceanSITES follows the philosophy and principles established by the Argo program. geostationary platforms, starting with the GOCI (Geostationary Ocean Color Imager) instrument aboard 
the Korean COMS-1 (Communication, Ocean and Meteorological Satellite 1) satellite. These highfrequency ( hourly) observations represent an avenue for the OCR community for the exploration of dailyscale processes including the possible quantification of primary production rates, at least at regional scale.

The production of long-term climate-quality data records (CQDRs) is an essential requirement for the OCR community. Associated to this are two important prerequisites. The first one is an uninterrupted OCR data stream, which is presently of great concern. For the near-future, while the continuity of the SeaWiFS, MODIS (Moderate Resolution Imaging Spectroradiometer) and MERIS (Medium Resolution Imaging Spectrometer) observations is possibly ensured thanks to the ESA (European Space Agency) Sentinel-3 and the ISRO (Indian Space Research Organization) OceanSat-2 missions, there are some concerns with potential critical delays in subsequent missions (e.g., NPP (National Polar-orbiting Operational Environmental Satellite System Preparatory Project) and NPOESS). The second essential condition is the consistency of the dataset of various sensors [24]. The climate-related signals that we need to measure are tiny and even the smallest differences in satellite calibration or data processing procedures can obfuscate these trends. Notably, this production of continuous and coherent OCR datasets is tightly dependant on the continuous availability of in situ calibration / validation datasets.

It is strongly advised that additional bands are added to future OCR satellites to better resolve in-water constituents (e.g. CDM and Chlorophyll, [69]), improve atmospheric correction and improve our ability to obtain information on community composition. Additionally inclusion of other spaceborn sensors (e.g. polarimeters and LIDAR) could provide more discrimination of particles [70 and 71] and their vertical distribution.

The merging of OCR products from various sensors is also a way to increase the spatial / temporal coverage of observations (Fig 6) and is potentially useful for operational applications. The NASA (National Aeronautics and Space Administration)-reason has merged SeaWiFS and MODIS-Aqua data into a single time series. The GlobColour Project has similarly merged MERIS, SeaWiFS and MODIS-Aqua data. Such merging efforts should be continued in the future.

\section{THE KEY OF THE SUCCESS: AGREED PROCEDURES, DATA MANAGEMENT AND DISTRIBUTION}

\subsection{In situ data acquired by autonomous platforms}

The technology for observing key oceanic biogeochemistry and ecosystem variables has progressively matured to the point where it is now

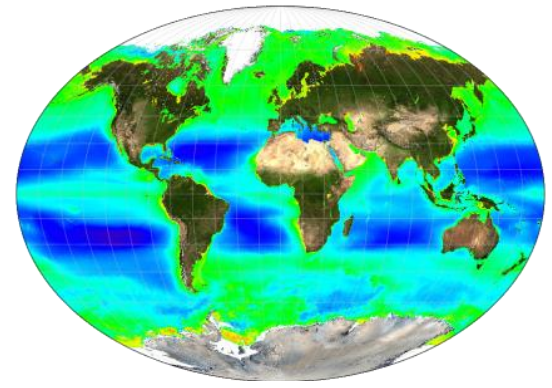

Figure 6: Example of an annual mean merged SeaWiFS-MODIS-MERIS product from a 1997 2006 climatology. From the GlobColour project.

amenable to a global dissemination. Additionally, data sources will be much more diverse than today, going essentially from ship-based data acquisition to an increased contribution of data acquired through remotely operated platforms. Within a few years, our community will thus acquire tremendous amounts of "bio" data. An integrated observation system will be operationally useful and scientifically relevant if and only if this huge data acquisition effort is supported by an efficient data management system able to meet both basic scientific and operational goals. Indeed the success in implementing these new cost effective technologies in our observation strategy will heavily rely on our capacity to make all data easily available.

Nevertheless, such a data management system is still to be designed and implemented. The important criteria that preclude this implementation are, notably, availability of real-time quality-controlled (QC) data for operational applications, production of delayed-mode QC data required for climate-related studies. In some ways, these perquisites are orthogonal to the historic habits or constraint with respect to "bio" data management. First of all, with the exception of satellite data, our community has not been used to the management of very large datasets because most "bio" data acquisition has been essentially based on discrete measurements performed from ship-based platforms. Secondly, there are generally some hurdles to make "bio" data publically available. While on-going efforts in this direction are underway [72], much remains to be done and the community has to consider this aspect of data management as a priority. Finally, and in corollary to the preceding point, our community is even less used to the constraints involved in the production and distribution of data in near-to-real-time.

A revolution is thus required in the way we manage data to guarantee public access and to deliver real-time data and products, when required. This likely represents the most challenging issue for our community, at least as 
challenging than the required technological developments themselves. Some good examples of rather efficient data management can be taken from nearby communities, for example, the OCR satellite community, the Argo community and the Ocean Biogeographic Information System which are pioneers in the organization and management of data on the distribution of marine species. The management of data within these communities is organized through common principles. (1) Operational data are delivered in near to real-time with associated quality control. (2) Delayed mode, interactive quality-controlled data are delivered with raw data reprocessing undertaken, if required. These data are of scientific value and compatible with the extraction of climatic trends. (3) Some derived products are produced and distributed by the data centers. (4) Raw data are publically available as well as the codes for their processing into products.

The system developed for Argo QC and management should thus serve as the basis for beginning the implementation of "bio" data management. A good example is the OceanSITES program that has an integrated core "bio" variable and which relies on the same Global Data Assembly Center (GDAC) as Argo for archiving [60], QC and distribution of data. GOSHIP [58] is also taking these programs as an example for organizing future ship-based hydrographic investigations. More generally Argo and OceanSITES should be the example followed for the management of data acquired by other types platforms especially floats, gliders and animals.

Even if Argo (or satellite OCR) data management can serve as the backbone of a future "bio" data management system, we have nevertheless to acknowledge that the specificity of "bio" data makes their management a much more complicated task than for physical variables (e.g. T, S from Argo), especially because of the diversity of ways for measuring variables. An example is Chla, the "universal" proxy of phytoplankton, which can be measured through several ways. Firstly it can be measured from space through reflectance ratios or fluorescence measurements. It can also be non-intrusively measured from in situ sensors (in vivo fluorescence, absorption) or through laboratory analysis (HPLC, spectrophotometry, fluorometry, spectrofluoro-metry) on filtered water samples. All together the concentration of Chla should represent the target "bio" product regardless the method of acquisition. Presently this is not the case and it is obvious that modelers can be lost when they try to access this fundamental variable from available databases. It is therefore mandatory to develop a unified format and language for "bio" data, which is an essential prerequisite for efficiently streamline and interfacing datasets.
Furthermore and upstream of data management it is worth recalling the necessity of conducting essential actions to guarantee the quality of the acquired data [73]. First of all it is essential to develop best-practice manuals in support of practical training and capacity building. The development of reference material for sensor calibration prior to platform deployment, as well as the support of regular international inter-comparison exercises is crucial. Ideally some internationally agreed calibrations centers for "bio" sensors should be also implemented.

\subsection{Satellite data}

The minimum requirement here is a free, easy, timely and sustained access to satellite-derived products. This statement might be read as an obvious one, whereas the present situation in terms of data availability is actually not optimal.

The rapid growth of the use of satellite ocean-color products in various fields of biogeochemical oceanography has been possible in the past decade because data have been made available efficiently to the entire science community, in particular from the NASA SeaWiFS and MODIS instruments. Data from other missions are still not so intensively used because of inappropriate data policies and distribution procedures, although the situation admittedly improved in the recent years. There is not a single satellite mission that can provide all needed information at all required temporal and spatial resolutions, however. This is due in particular to the specifics of orbits, swath widths and other mission characteristics, and also to the finite and often short lifetime of satellite missions compared with the time scales of many phenomena of interest. The key here is the merging of data from multiple missions.

The first requirement is, therefore, that liberal data policies be adopted by space Agencies, so that data from multiple sensors are available for use, exchange, comparison and eventually merging. An appropriate data policy can be overwhelmed, however, by deficient ground segment capabilities for data distribution. Therefore, the mandatory corollary of an open data policy is a well-dimensioned online data distribution system [73].

The second requirement is that all needed information and data on instruments characterization, calibration techniques, data processing algorithms etc., be made available, in parallel to the geophysical products. This is mandatory to achieve a meaningful data merging. The corollary of such a requirement is the need for a location (virtual or otherwise) where information is gathered, centralized and made available, so the final objective of building climate quality data records is realized. This can be either an organization, or a project which does not exist today. 


\section{TOWARDS INTEGRATION}

When referring to integration of the various elements (in situ measurements, satellite measurements, models) into a sustained observation system, the development of synergy immediately arises: how to set up the integrated system in such a way that its usefulness for science and operational activities is superior to that of the various elements taken individually (see also the way of approaching integration in [74]). Several lines of integration can be envisaged in this context.

\subsection{Bio-physical integration}

In the late eighties-early nineties, when the JGOFS program started, two rather distinct communities coexisted, the biological and the geochemical ones. It took more than one decade for both communities to learn modalities of working together, resulting in the development of a real biogeochemical community. This community is now mature and has begun to develop observational tools with a spatial or temporal resolution similar to that used for the observation of physical fields.

Integration of a biological component into an already existing physical observational system, however, is not just a matter of adding "bio" sensors to this system. Because "bio" processes strongly depend on physical forcing at all scales, a "bio" program of observation ("bio" Argo, "bio" Glider, "bio" Time series...) should not be a side program, independent of the corresponding physical program. Optimally, it should be clearly defined and then implemented in close association with physical oceanographers. However, whereas ocean biology depends on physics the reverse is not (generally) true and hence biogeochemical topics are perhaps in some instances, not sufficiently attractive for physical oceanographers. Nevertheless, the possibility to acquire "bio" data at high frequency might change this a priori weak interest: common scientific objectives have to be identified by both communities as a way to develop truly integrated bio-physical observational approaches which can take advantage of the emerging technologies.

The operational maturity of gliders developed more or less simultaneously with the operational maturity of biogeochemical / bio-optical sensors. Furthermore, the spatial domain covered by gliders encompasses the submeso and mesoscales, which are critical for biogeochemistry and physics; the development of real bio-physical synergetic approaches based on the use of gliders is naturally progressing. The same applies for animals with physical and "bio" sensors.

For time series and ship-based hydrography, following the initial inclusion of variables of the $\mathrm{CO}_{2}$ system, new "bio" core variables are now implemented into the physical observation system [58 and 60]. Thus, new studies at the interface of physics and biogeochemistry can be undertaken for a better understanding of the driving mechanisms of biologically mediated carbon fluxes, from the diel to the decennial scales (time series) or at a regional/basin scale (ship-based repeated transects).

Developing coupled approaches between physical and biogeochemical oceanographers based on the use of float technology appears a priori less obvious. The Argo program is well organized and mature, while the "bio" counterpart is in infancy. Adding "bio" variables to the overall system might be seen as technically challenging, costly, and generating issues related to the law of the sea. However there are mutual advantages both communities working together. The addition of "bio" variables will require Iridium transmission. The additional bandwidth provides the ability to collect addition data, for example, the ability to resolve meterscales in the vertical, essential when accurate mixed layer estimation is a target. Similarly phytoplankton content in upper layers affects their heating rates (one rare if not the sole feedback of biology on physics!). Topics related to biological response to mixed layer dynamics (from the event to the seasonal and interannual time scale) represent an interdisciplinary topic for synergy between both communities.

\subsection{Synergy between in situ "bio" data and OCR satellite data.}

Building an observing system with a global scope inevitably requires the inclusion of satellite remote sensing observations. Modern ocean observing networks will be built as an aggregate of ship-based observations along with observations from mooring sites and various autonomous platforms, such as floats and gliders. Remote-sensing observations are the appropriate element needed to integrate inherently-localized information into a basin-scale context, and to embed them into the long-term view progressively built from past, present and future satellite archives.

However, remote sensing does not stand alone. All remote sensing techniques, such as infrared radiometry for the determination of SST (Sea Surface Temperature) or visible and near infrared spectral radiometry (VSR) for the determination of ocean color, require in situ data for calibration of the radiometric observations recorded at the top of the atmosphere, and for validation of the final "geophysical products" derived from these observations (reflectances, chlorophyll concentration, SST etc.). In addition, remote-sensing techniques are far from being frozen, in the sense that algorithms used to derive the geophysical products of interest need periodic improvements. This is mandatory to improve the quality of existing products and to derive new, advanced products to maximize the benefits from the satellite information. In this context also, in situ data play a 
central role. This is the first mode of complementarity between in situ and satellite observations.

The second aspect is when field observations are available in areas that are hardly observable by remote sensing because of clouds and low sun angles and at depth in the ocean. The third aspect is linked to the nature of the satellite OCR observations, which allow retrieval of biogeochemical quantities within the upper oceanic layer. This layer is typically the one-fifth of the so-called euphotic layer, which itself varies from a few meters in eutrophic areas to $\sim 160 \mathrm{~m}$ in the clearest waters [75]. Therefore in situ data are essential to complement fields of satellite data and to extend them into the ocean interior [76].

This complementarity will allow the development of 3D / 4D views of key "bio" variables in the world ocean. These aggregated datasets will serve to evaluate the performance of coupled physical-biogeochemical models at various scales, and to identify and quantify seasonal, inter-annual and multi-decadal variability and trends. Additionally, these 3D fields will also constitute the "initial climatologies" that will serve as baseline to establish delayed-mode data quality control for "bio" data (e.g. Chla, POC) acquired by "bio" sensors on autonomous platforms.

Therefore, there is a permanent exchange between satellite remote sensing, field oceanography, and numerical modeling with mutual benefits. Long-term global ocean observing systems are the crucible within which this tight coupling between fundamental research in marine optics and bio-optics, ocean color remote sensing science and applications, and biogeochemical oceanography can develop.

\subsection{Data-model integration}

The rapidly evolving field of data assimilation holds great promise to integrate operational models and a wide variety of data sources. Most of this work has taken place within meteorology, and more recently physical oceanography, but recent successes with assimilation of biogeochemical data are evident [17].

Dynamic Green Ocean Models are also important integrators of observations, as they require a large amount of data to constrain the various rates and validate the model output. Some efforts to compile and analyze the relevant data are already underway [16], but there are many obstacles to overcome before the community makes full use of existing data, and before the data collected covers all necessary information. In particular, models typically represent biomass in units of carbon concentration, whereas collected data are most often represented in term of abundance. Models also require global coverage and time-varying information. Nevertheless, despite the problems of coverage and units that exist actually, it is encouraging that global models already roughly represent large groups of phytoplankton and zooplankton in regions where they are observed and expected [77, 78 and 79]. The models can thus already begin to provide answers regarding the processes that control ecosystems [80]. However systematic validation of Dynamic Green Ocean Models is not yet performed systematically (partly but not entirely due to the lack of appropriate observations), and therefore much integration between data and models remains to be done before models can be seen to provide reliable projections of the state of marine ecosystems and their influence on climate. Progress should be achieved through the new MARine Ecosystem Model Intercomparison Project (MAREMIP), an international effort to co-ordinate the developments and use of Dynamic Green Ocean Models. Such large international projects need to be done in close collaboration with observationalists, and in return it needs to feedback information regarding data needs to the observing community.

\subsection{A step towards global integration: conducting process studies at «super-sites».}

At the moment, the "bio" community is deeply engaged in maturing the various platforms of the observation system. Developing a synergetic interplay of these various "bio" platforms into a sustainable integrated observation system will only be successful if the system is designed to respond to well-addressed scientific questions. The sizing of the system (density of "bio" gliders, "bio" floats, "bio" animals...) and the synergistic integration of these various elements will become more natural and easy to implement as soon as these questions and associated relevant spatio-temporal scales are clearly identified.

An example of an integrated approach of the open ocean biogeochemistry and ecosystems can be represented by the JGOFS era. The main question of the JGOFS program was to understand and quantify the so-called oceanic biological pump. To achieve this goal, several key oceanic provinces were selected and "process study" cruises conducted where relationships between autotrophic biomass, carbon fixation and export could be established and quantified. These relationships provide a basis on which to establish parameterization of global biogeochemical models. In its ultimate phase (synthesis and modeling activities), the main goal of JGOFS was to use these models to estimate carbon export flux from observations of the upper ocean Chla and POC, the only variables accessible at the global scale. Unfortunately, JGOFS process studies were mostly conducted after the end of CZCS (Coastal Zone Color Scanner) (1983) and before the beginning of the SeaWiFS (1997) era. Additionally, no autonomous platforms were available at that time. Nevertheless, the JGOFS program remains the main coordinated and 
integrated observational effort to date to observe and understand marine biogeochemical cycles.

While the global ocean would appear the natural target to set up a long-term and sustained observation system, the implementation of pilot studies on regional "hotspot(s)" or super-sites [74], based on the example of international coordination developed during JGOFS, appears as the first and most reasonable step towards integration. There are indeed regional "hot-spots" that are natural laboratories for addressing key scientific questions of global relevance, and which would benefit from being tackled in a highly integrated way. Two examples can be highlighted of such "super-sites".

Eastern boundary currents are highly dynamic locations with enhanced biological and biogeochemical activity. These generally extremely eddy-rich areas exhibit active upwelling and consequently intense fishery activities. Additionally the intermediate layers in these areas are characterized by the presence of oxygen minimum zones (OMZs) which impact the carbon and nitrogen cycles. The size of the OMZs is presently increasing (ocean deoxygenation) as a consequence of ocean warming and increased stratification. This reduction in oxygen level may have dramatic consequences for biodiversity and coastal economies. It is therefore timely and very opportune to take benefit from the new multiscale and multivariate capabilities of the various platforms to design a long term integrated observation system of an eastern boundary current system and its associated OMZ.

A second example is the North Atlantic. Despite representing only $1.4 \%$ of the ocean's area, the North Atlantic (northward of $50^{\circ} \mathrm{N}$ ) accounts for about $20 \%$ of the global ocean carbon sink [81] and is the site of the largest spring / summer phytoplankton bloom in the global ocean. The magnitude of the $\mathrm{CO}_{2}$ sink presents strong inter-annual variability [82] and recent studies have documented its decrease [83]. To what degree this decrease results from natural oscillation (e.g. North Atlantic Oscillation, NAO, [84]) in the rates of wintertime mixing and ventilation, or from the response of biological activity to global warming and associated progressive stratification remains to be assessed. The design of a multiplatform observational approach sustained over the long-term is the only adequate response to resolve this key question.

\subsection{Global integration requires capacity building efforts.}

Two-thirds of the world oceans are in the southern hemisphere, and most of the capacity for ocean observation is in the northern hemisphere. To ensure that all nations benefit from enhanced ocean observations, capacity building is required, not only in the developed countries of the northern hemisphere, but also in all developing coastal nations of the world. The capacity-building efforts that are currently underway through international organizations such as the Partnership for Observation of the Global Oceans (POGO), the Group on Earth Observations (GEO), Scientific Committee for Oceanic Research (SCOR) and the Intergovernmental Oceanographic Commission (IOC) have to be sustained and developed, to ensure optimal and wide-spread use of ocean observations. Note that previous capacity-building efforts are already yielding fruit, for example in the world-wide networking for chlorophyll and related ecosystem observations using in situ and remote platforms [70]. It is also worth bearing in mind that in designing an integrated observation system, one should not overlook the importance of simple, tried-and-tested methods of observation that are simple-to-use and easy-to-sustain. This facilitates the participation of developing countries, and ensures a baseline of simple observations across the world oceans, over which more sophisticated observations can be built. The value of sustained ocean observations will depend ultimately not only on its scientific merit, but above all on its usefulness to the society at large. Therefore, building the system has to go hand in hand with building capacity to use the information for societal applications. The applications go beyond issues of global relevance such as climate change, to those of local and regional importance, including water quality, biodiversity, sustainable and ecosystem-based management of living resources.

\section{FINAL RECOMMENDATIONS}

There are several key elements that are perquisite for guaranteeing the success of a future integrated system. Here, we briefly summarize them.

The implementation of the observation system relies on the critical choice of the "bio" variables. The community first has to begin with few variables, chosen for their scientific relevance as well as the technological maturity of their autonomous measurements. Thereafter, the observation system could be progressively developed with the addition of new variables satisfying both criteria.

This in situ system should be fully designed and implemented in tight synergy with satellite ocean color radiometry as well as advanced numerical models of biogeochemical cycles and ecosystems.

The sustainability of the entire system will depend on the capability of our community to implement a dedicated data management system. Open access data and quality control in real-time as well as in delayedmode are the keywords of this challenging and ambitious task.

The possibility to measure "bio" fields with the same spatio-temporal resolution than the physical ones (and if possible, synoptically in time and space) pleads for the 
development of truly integrated bio-physical scientific approaches that can be developed for the first time. This is highly desirable because "bio" fields are forced and driven, to first order, by physics. Therefore the integrated system has to be clearly defined and then implemented in close association with physical oceanographers, a perquisite for developing synergies between both communities.

Finally the community should begin "simple" and consider the observation of "super sites" in key areas of global relevance as a first step towards global integration.

\section{REFERENCES}

1. Munk, W. M. 2000. Oceanography before, and after, the advent of satellites, p. 1-4. In D. Halpern [ed.], Satellites, oceanography and society. Elsevier.

2. Freeland, H. \& Co-Authors (2010). "Argo - A Decade of Progress" in these proceedings (Vol. 2), doi:10.5270/OceanObs09.cwp.32.

3. Körtzinger, A., J. Schimanski, U. Send, and D. Wallace. 2004. The Ocean takes a deep breath. Science, 306: 1337.

4. Boss, E. \& Co-Authors (2008). Observations of pigment and particle distributions in the western North Atlantic from an autonomous float and ocean color satellite. Limnol. Oceanogr., 53, 2112-2122.

5. Bishop, J. K. B., \& Wood T. J. (2009). Year-round observations of carbon biomass and flux variability in the Southern Ocean. Global Biogeochem. Cycle, 23, GB2019, doi:10.1029/2008GB003206.

6. Davis, R., Ohman, M. D., Rudnick, D.L., Sherman J. \& Hodges, B. (2008). Glider surveillance of physics and biology in the southern California Current System, Limnol. Oceanogr., 53, 2151-2168.

7. Perry, M. J., Sackmann, B. S., Eriksen, C. C., \& Lee, C. M. (2008). Seaglider observations of blooms and subsurface chlorophyll maxima off the Washington coast. Limnol. Oceanogr., 53, 2169-2179.

8. Niewiadomska, K., Claustre, H., Prieur, L. \& D'Ortenzio, F. (2008). Submesoscale physical-biogeochemical coupling across the Ligurian current (northwestern Mediterranean) using a bio-optical glider. Limnol. Oceanogr., 53, 2210-2225.

9. Boehme, L. \& Co-Authors (2010). "Biologging in the Global Ocean Observing System" in these proceedings (Vol. 2), doi:10.5270/OceanObs09.cwp.06.

10. Claustre, H. \& Co-Authors (2010). "Bio-Optical Profiling Floats as New Observational Tools for Biogeochemical and Ecosystem Studies: Potential Synergies with Ocean Color Remote Sensing." in these proceedings (Vol. 2), doi:10.5270/OceanObs09.cwp.17.
11. Gruber, N. \& Co-Authors (2010). "Adding Oxygen to Argo: Developing a Global In Situ Observatory for Ocean Deoxygenation and Biogeochemistry" in these proceedings (Vol. 2), doi:10.5270/OceanObs09.cwp.39.

12. Johnson, K.S., Berelson, W.M., Boss, E.S., Chase, Z., Claustre, H., Emerson, S.R., Gruber, N., Körtzinger, A., Perry, M.J. \& Riser, S.C. (2009). Observing biogeochemical cycles at global scales with profiling floats and gliders: prospects for a global array. Oceanography, 22, 216-225.

13. Testor, P. \& Co-Authors (2010). "Gliders as a Component of Future Observing Systems" in these proceedings (Vol. 2), doi:10.5270/OceanObs09.cwp.89.

14. Gruber, N. \& Co-Authors (2010). "Towards an Integrated Observing System for Ocean Carbon and Biogeochemistry at a Time of Change" in these proceedings (Vol. 1), doi:10.5270/OceanObs09.pp.18.

15. Fasham, M. J. R., Ducklow, H. W. \& Mckelvie, S. M. (1990). A nitrogen-based model of plankton dynamics in the oceanic mixed layer. J. Mar. Res., 48, 591-639.

16. Le Quéré, C. \& others (2005). Ecosystem dynamics based on plankton functional types for global ocean biogeochemistry models, Global Change Biol., 11, 2016-2040, doi: 10.1111/j.1365-2486.2009.02071.x.

17. Brasseur, P. \& Co-Authors (2009). Integrating biogeochemistry and ecology into ocean data assimilation systems. Oceanography, 22, 206-215.

18. Le Quéré, C. \& Co-Authors (2010 ). "Observational Needs of Dynamic Green Ocean Models" in these proceedings (Vol. 2), doi:10.5270/OceanObs09.cwp.56.

19. Yoder, J. A., \& Kennelly, M. A. (2003). Seasonal and ENSO variability in global ocean phytoplankton chlorophyll derived from 4 years of SeaWiFS measurements. Global Biogeochem. Cyc., 17, 1112, 11, doi:10.1029/2002gb001942.

20. Longhurst, A., Sathyendranath, S., Platt, T., \& Caverhill, C. (1995). An estimate of global primary production in the ocean from satellite radiometer data. J. Plankton Res., 17, 1245-1271.

21. Antoine, D., André, J. M. \& Morel, A. (1996). Oceanic primary production 2. Estimation at global scale from satellite (coastal zone color scanner) chlorophyll. Global Biogeochem. Cycles, 10, 57-69.

22. Behrenfeld, M. J., \& Falkowski, P. G. (1997). Photosynthetic rates derived from satellite-based chlorophyll concentration. Limnol. Oceanogr., 42, 120.

23. Behrenfeld, M. J., Boss, E., Siegel, D. A., \& Shea D. M. (2005). Carbon-based ocean productivity and phytoplankton physiology from space. Global Biogeochem. Cycles, 19, GB1006, doi:10.1029/2004GB002299.

24. Antoine, D., A. Morel, H. R. Gordon, V. F. Banzon, and R. H. Evans (2005), Bridging ocean color observations 
of the 1980s and 2000s in search of long-term trends, J. Geophys. Res., 110, C06009, doi:10.1029/2004JC002620.

25. Polovina, J. J., Howell, E.A. \& Abecassis, M. (2008). Ocean's least productive waters are expanding, Geophys. Res. Lett., 35, L03618, doi:10.1029/2007GL031745.

26. Devred, E., Sathyendranath, S. \& Platt, T. (2009). Decadal changes in ecological provinces of the Northwest Atlantic Ocean revealed by satellite observations. Geophys. Res. Lett. 36, L19607, doi:10.1029/2009GL039896.

27. Martinez E., Antoine, D., D'Ortenzio, F. \& Gentili, B. (2009). Climate-driven basin-scale decadal oscillations of oceanic phytoplankton, Science, 36, $1253-1256$

28. Nair, A. \& Co-Authors (2010). Remote sensing of phytoplankton functional types. Rem. Sens. Env., 112, 3366-3375.

29. MacCready, P., \& Quay, P. (2001). Biological export flux in the Southern Ocean estimated from a climatological nitrate budget. Deep-Sea Res. Part II, 48, 4299-4322.

30. Johnson, K. S. \& Coletti, L. J. (2002). In situ ultraviolet spectrophotometry for high resolution and long term monitoring of nitrate, bromide and bisulfide in the ocean. Deep-Sea Res. I, 49, 1291-1305.

31. Sakamoto, C. M. \& Co-Authors (2004). Influence of Rossby waves on nutrient dynamics and the plankton community structure in the North Pacific subtropical gyre. J. Geophys. Res., 109, doi:10.1029/2003JC001976.

32. Johnson, K. S., \& Needoba, J. A. (2008). Mapping the spatial variability of plankton metabolism using nitrate and oxygen sensors on an autonomous underwater vehicle. Limnol. Oceanogr., 53, 2237-2250

33. Körtzinger, A., Send, U., Wallace, D.W.R., Karstensen, J. \& DeGrandpré, M. (2008). The seasonal cycle of $\mathrm{O}_{2}$ and $p \mathrm{CO}_{2}$ in the central Labrador Sea: Atmospheric, biological and physical implications. Global Biogeochem. Cycles, 22, GB1014, doi:10.1029/2007GB003029.

34. Körtzinger, A. \& Co-Authors (2008). The seasonal $p \mathrm{CO}_{2}$ cycle at $49^{\circ} \mathrm{N} / 16.5^{\circ} \mathrm{W}$ in the northeast Atlantic Ocean and what it tells us about biological productivity. $J$. Geophys. Res., 113, C04020, doi:10.1029/2007JC004347.

35. Brasseur, L., Tamburri, M. and Pluedemann, A., (2010). "Sensor Needs and Readiness Levels for Ocean Observing: An Example from the Ocean Observatories Initiative (OOI)" in these proceedings (Vol. 2), doi:10.5270/OceanObs09.cwp.10.

36. Byrne, R. \& Co-Authors (2010). "Sensors and Systems for In Situ Observations of Marine Carbon Dioxide System Variables" in these proceedings (Vol. 2), doi:10.5270/OceanObs09.cwp.13.
37. Monteiro, P. \& Co-Authors (2010). "A Global Sea Surface Carbon Observing System: Assessment of Changing Sea Surface CO2 and Air-Sea CO2 Fluxes" in these proceedings (Vol. 2), doi:10.5270/OceanObs09.cwp.64.

38. Oelßner, W., \& Co-Authors (2005). Encapsulation of ISFET sensor chips. Sens. Actuators B, 105, 104-117.

39. Adornato, L. \& Co-Authors (2010). "In Situ Nutrient Sensors for Ocean Observing Systems" in these proceedings (Vol. 2), doi:10.5270/OceanObs09.cwp.01.

40. Sieracki, M. \& Co-Authors (2010). "Optical Plankton Imaging and Analysis Systems for Ocean Observation" in these proceedings (Vol. 2), doi:10.5270/OceanObs09.cwp.81.

41. Checkley D. M., \& Co-Authors (2008) Assessing plankton and other particles in situ with the SOLOPC. Limnol. Oceanogr., 53, 2123-2136.

42. Sosik, H.M. \& Olson, R. J. (2007). Automated taxonomic classification of phytoplankton sampled with imagingin-flow cytometry. Limnol. Oceanogr. Meth., 5, 204216.

43. Grosjean, P., Picheral, M., Warembourg, C., \& Gorsky, G. (2004). Enumeration, measurement, and identification of net zooplankton samples using the ZOOSCAN digital imaging system. ICES J. Mar. Sci., 61, 518525 .

44. Hu, Q. \& Davis, C. (2006). Accurate automatic quantification of taxa-specific plankton abundance using dual classification with correction. Mar. Ecol. Prog. Ser., 306, 51-61.

45. Guay, C. K. H. \& Bishop, J. K. B. (2002). A rapid birefringence method for measuring suspended CaCO3 concentrations in seawater. Deep-Sea Res., 49, 197-210.

46. Makris, N. C., Ratilal, P., Symonds, D. T., Jagannathan, S., Lee, S. \& Nero, R. W. (2006). Fish Population and Behavior Revealed by Instantaneous Continental Shelf-Scale Imaging, Science, 311, 660-663.

47. Holliday, D. V., Donaghay, P. L., Greenlaw, C. F., Napp, J. M. \& Sullivan, J. M. (2009). High-frequency acoustics and bio-optics in ecosystems research. ICES J. Mar. Sci., 66, 974-980

48. FAO (2003). The ecosystem approach to fisheries, FAO Technical guidelines for responsible fishing, 4 Suppl. 2,. 112 pp. ftp://ftp.fao.org/docrep/fao/005/y4470e/y4470e00.pdf

49. Lehodey, P., Senina, I., \& Murtugudde, R. (2008). A spatial ecosystem and populations dynamics model (SEAPODYM) - Modeling of tuna and tuna-like populations. Prog. Oceanogr., 78, 304-318.

50. Mac Lennan, D. \& Simmonds, E. (2005). Fisheries Acoustics. Chapman \& Hall.

51. Handegard, N. \& Co-Authors (2010). "Toward a Global Ocean Ecosystem Mid-Trophic Automatic Acoustic 
Sampler (MAAS)" in these proceedings (Vol. 2), doi:10.5270/OceanObs09.cwp.40.

52. Trevorrow, M.V. (2005). The use of moored inverted echo sounders for monitoring meso-zooplankton and fish near the ocean surface. Canadian Journal of Fisheries \& Aquatic Sciences, 62, 1004-1018.

53. Riser, S. C., \& Johnson K. S. (2008). Net production of oxygen in the subtropical ocean. Nature, 451, 323325 .

54. Levy, M., Klein, P. \& Ben Jelloul, M. (2009). New production stimulated by high-frequency winds in a turbulent mesoscale eddy field. Geophys. Res. Lett., 36, L16603, doi:10.1029/2009GL039490.

55. Charrassin, J. \& Co-Authors (2010). "New Insights into Southern Ocean Physical and Biological Processes Revealed by Instrumented Elephant Seals" in these proceedings (Vol. 2), doi:10.5270/OceanObs09.cwp.15.

56. Nicholls, K.W., Boehme L., Biuw M., \& Fedak, M.A. (2008). Wintertime ocean conditions over the southern Weddell Sea continental shelf, Antarctica, Geophys. Res. Lett. 35, L21605, doi:10.1029/2008GL035742.

57. Teo S. L. H., Kudela, R. M., Rais, A., Perle, C., Costa, D.P., \& Block, B. A. (2009) Estimating chlorophyll profiles from electronic tags deployed on pelagic animals. Aquat. Biol. 5, 195-207

58. Hood, M. \& Co-Authors (2010). "Ship-Based Repeat Hydrography: A Strategy for a Sustained Global Program." in these proceedings (Vol. 2), doi:10.5270/OceanObs09.cwp.44.

59. Feely, R. \& Co-Authors (2010). "An International Observational Network for Ocean Acidification" in these proceedings (Vol. 2), doi:10.5270/OceanObs09.cwp.29.

60. Send, U. \& Co-Authors (2010). "OceanSITES" in these proceedings (Vol. 2), doi:10.5270/OceanObs09.cwp.79.

61. Doney, S. C., Glover, D. M., Mccue, S. J. \& Fuentes M. (2003). Mesoscale variability of Sea-viewing Wide Field-of-view Sensor (SeaWiFS) satellite ocean color: Global patterns and spatial scales. J. Geophys. Res., 108, 3024, doi:10.1029/2001JC000843.

62. Zhai, L., Platt, T., Tang, C., Dowd, M., Sathyendranath, S. \& Forget, M. H. (2008). Estimation of phytoplankton loss rate by remote sensing. Geophys. Res. Lett., 35: doi:10.1029/2008g1035666.

63. Stramski, D. \& Co-Authors (2008). Relationships between the surface concentration of particulate organic carbon and optical properties in the eastern South Pacific and eastern Atlantic Oceans. Biogeosciences, 5, 171-201.

64. Siegel, D. A., Maritorena, S., Nelson, N. B., Hansell, D. A., \& Lorenzi-Kayser, M. (2002). Global distribution and dynamics of colored dissolved and detrital organic materials. J. Geophys. Res., 107, 3228, doi:10.1029/2001JC000965.
65. Brown, C. A., Huot, Y., Werdell, P. J., Gentili, B. \& Claustre, H. (2008). The origin and global distribution of second order variability in satellite ocean color and its potential applications to algorithm development, Rem. Sens. Env., 112, 4186-4203, doi:10.1016/j.rse.2008.06.008.

66. Loisel, H., Nicolas, J. M., Sciandra, A., Stramski, D. \& Poteau A. (2006). Spectral dependency of optical backscattering by marine particles from satellite remote sensing of the global ocean. J. Geophys. Res., 111, C09024, doi:10.1029/2005JC003367.

67. Alvain, S., Moulin, C., Dandonneau, Y. \& Breon F. M. (2005). Remote sensing of phytoplankton groups in case 1 waters from global SeaWiFS imagery. Deep Sea Res. I, 52, 1989-2004.

68. Uitz, J., Claustre, H., Morel, A., \& Hooker, S. (2006). Vertical distribution of phytoplankton communities in open ocean: an assessment based on surface chlorophyll. J. Geophys. Res., 111, C08005, doi:10.1029/2005JC003207.

69. Siegel, D. A., Maritorena, S. Nelson, N. B. \& Behrenfeld, M. J. (2005). Independence and interdependencies among global ocean color properties: Reassessing the bio-optical assumption. J. Geophys. Res., 110, 1-14. doi:10.1029/2004JC002527.

70. Chami M. (2007). Importance of the polarization in the retrieval of oceanic constituents from the remote sensing reflectance, J. Geophys. Res., 112, C05026, doi:10.1029/2006JC003843.

71. Loisel, H., L. Duforet, D. Dessailly, M. Chami \& Dubuisson P. (2008). Investigation of the variations in the water leaving polarized reflectance from the POLDER satellite data over two biogeochemical contrasted oceanic areas. Optics Express, 16, 1290512918.

72. Le Quéré, C. \& Pesant, S. (2009). Plankton functional types in a new generation of biogeochemical models. EOS, 90, 30-31.

73. Keeley, R., Woodruff, S., Pouliquen, S., Conkright-Gregg, M. and Reed, G., (2010). "Ocean Data: Collectors to Archives" in these proceedings (Vol. 1), doi:10.5270/OceanObs09.pp. 25.

74. Send, U. \& Co-Authors (2010). "Towards an Integrated Observing System: In Situ Observations" in these proceedings (Vol. 1), doi:10.5270/OceanObs09.pp.35.

75. Morel, A., Claustre, H., Antoine, D. \& Gentili, B. (2007). Natural variability of bio-optical properties in Case 1 waters: attenuation and reflectance within the visible and near-UV spectral domains, as observed in South Pacific and Mediterranean waters. Biogeosciences, 4, 913-925

76. Sathyendranath, S. \& Co-Authors (2010). "ChloroGIN: Use of Satellite and In Situ Data in Support of Ecosystem-Based Management of Marine Resources" in these proceedings (Vol. 2), doi:10.5270/OceanObs09.cwp.75. 
77. Moore, K.J., Doney, S.C., Kleypas, J.A., Glover, D.M. \& Fung, I.Y. (2002). An intermediate complexity marine ecosystem model for the global domain. Deep-Sea Research, 49, 403-492.

78. Gregg, W.W. \& Casey, N.W. (2007). Modeling coccolithophores in the global oceans. Deep-Sea Research, 54, 447-477

79. Buitenhuis, E.T. \& Co-Authors (2006) Biogeochemical fluxes through mesozooplankton. Global Biogeochem. Cycle, 20, GB2003, doi:10.1029/2005gb002511.

80. Follows, M.J., Dutkiewicz, S., Grant, S. \& Chisholm, S.W. (2007). Emergent biogeography of microbial communities in a model ocean. Science, 315, 18431846.

81. Takahashi, T. \& Co-Authors (2009). Climatological mean and decadal change in surface ocean $\mathrm{pCO}(2)$, and net sea-air CO2 flux over the global oceans. Deep-Sea Res. Part II, 56, 554-577.

82. Corbière, A., Metzl, N., Reverdin, G., Brunet, C. \& Takahashi, A. (2007). Interannual and decadal variability of the oceanic carbon sink in the North Atlantic subpolar gyre Tellus B, 59, doi:10.1111/j.1600-0889.2006.00232.x.

83. Schuster, U. \& Watson A. J. (2007). A variable and decreasing sink for atmospheric $\mathrm{CO} 2$ in the North Atlantic. J. Geophys. Res., 112, doi:10.1029/2006JC003941.

84. Thomas, H. \& Co-Authors (2008). Changes in the North Atlantic Oscillation influence CO2 uptake in the North Atlantic over the past 2 decades. Global Biogeochem. Cycles, 22, doi:10.1029/2007GB003167. 